DOI: $10.5455 / 2320-1770$. ijrcog20141204

\title{
Role of fetal monitoring in high risk pregnancy by fetal electrocardiogram
}

\author{
Somya Girish Goyal, Parul T. Shah, Kruti Jignesh Deliwala*
}

\begin{abstract}
Department of Obstetrics \& Gynaecology, Smt N H L Municipal Medical College, Sheth V S General Hospital, Gujarat University, Ahmedabad-380009, Gujarat, India
\end{abstract}

Received: 14 August 2014

Accepted: 11 September 2014

\section{*Correspondence:}

Dr. Kruti Jignesh Deliwala,

E-mail: jadeliwala@yahoo.co.in

Copyright: (c) the author(s), publisher and licensee Medip Academy. This is an open-access article distributed under the terms of the Creative Commons Attribution Non-Commercial License, which permits unrestricted non-commercial use, distribution, and reproduction in any medium, provided the original work is properly cited.

\begin{abstract}
Background: Non-stress test is an external monitoring of fetal heart rate by electrocardiograph. Although intermittent auscultation of fetal heart rate is equivalent to continuous electronic fetal monitoring in detecting fetal compromise ${ }^{1}$ but continuous electronic fetal monitoring is indicated in high risk patients women whose foetuses are at high risk for neonatal encephalopathy or cerebral palsy. ${ }^{2}$ Objective of current study was to study the efficacy and diagnostic value of non-stress Test for surveillance and its usefulness to detect fetal distress at early stage which help to decide further management in mode of delivery.

Methods: Design: prospective study. NST was done in 50 high risk patients for minimum of 20 minutes and in patients with non-reactive non stress test it was continued for 40 minutes. Maternal age, parity, complications during labour, and delivery, mode of delivery, indications of caesarean section and perinatal outcome were noted.

Results: Out of total 50 cases studied patient delivered vaginally were 24 and Caesarean was done in 26 cases. Most LSCS were performed due to PIH (35\%) and related complications like IUGR, eclampsia (10\%), fetal distress, previous caesarean pregnancy, IUGR, oligohydraminos and meconium stained liquor. 52\% patients were delivered by caesarean and $48 \%$ by normal delivery.

Conclusions: Routine use of electronic fetal heart monitoring helped in reduction of neonatal morbidity and mortality with increased rate of caesarean section.
\end{abstract}

Keywords: Fetal monitoring, High risk pregnancy, Fetal electrocardiogram

\section{INTRODUCTION}

Ante partum fetal surveillance is beneficial in all patients and specially in high risk pregnancies like pregnancy induced hypertension, anaemia, diabetes mellitus, oligohydraminos to obtain better fetal outcome.

Fetal hypoxia and acidosis can be detected at early stage of pregnancy to avoid further complication and hence to reduce fetal morbidity and mortality.

The interpretation of NST for ante partum evaluation is presence of acceleration of fetal heart rate with foetal movement which indicates intact and responsive central nervous system. Non stress test is easy to use, less expensive, non-invasive and its interpretation is easy.

\section{High risk pregnancy include $:^{3}$}

Pregnancy induced hypertension, abruptio placentae, eclampsia, placenta praevia, postdate pregnancy, oligohydraminos, previous caesarean pregnancy, anaemia, premature rupture of membranes, gestational diabetes, intra uterine growth retardation, $\mathrm{Rh}$ isoimmunisation. 


\section{METHODS}

This is a prospective study of 50 high risk pregnancies who were attending antenatal outdoor department and admitted in our tertiary care institute in department of obstetrics and gynaecology. Study was conducted from January 2013 to December 2013. Study included all high risk patients with gestational age 32 weeks and more. Data of all patients was recorded as per proforma and analyzed as per age, parity, period of gestation at the time of diagnosis, high risk factors, results of NST, mode of delivery, baby's status APGAR score and perinatal outcome was noted.

\section{Procedure}

Patient is placed in semi fowler position keeping pillow under both the hips to avoid pressure on inferior vena cava.

Test is considered reactive when two or more than two accelerations in FHR were recorded in 20 minutes period with each acceleration of $>15$ beats per minute and lasting for more than 15 seconds.

We can continue current method of monitoring if no spontaneous fetal movement occurs in 20 minutes of observation. Then fetal movement is provoked by external manipulation.

If still no acceleration with spontaneous or repeated external stimuli, test is repeated for 40 minutes and if during 40 minutes no acceleration is present, test is nonreactive.

When no FHR accelerations are seen after fetal stimulation or FHR decelerations are seen without absent variability or no variability seen with decelerations in FHR, general measures are taken of giving oxygenation changing to left lateral position giving iv fluids by starting ringer lactate and oxytocin is discontinued if started and delivery is done as soon as possible.

Interpretation is done as follows

\section{Criteria for reactivity}

\section{Reactive tracing}

at least two acceleration with amplitude more than $15 \mathrm{bpm}$ for 15 seconds in 20 minutes. ${ }^{4}$ Usually associated with episode of fetal movements and normal baseline variability.

\section{Non-reactive tracing}

Tracing with no FHR acceleration or inadequate acceleration that is $<15 \mathrm{bpm}$ or decreased FHR variability. $\circ$ Sinusoidal $^{5}$

- Superimposed on non-reactive pattern.

- Smooth undulating FHR pattern with a baseline FHR stable at 120-160 bpm.

- amplitude of 5-15 bpm in 15 minutes.

- Flat short term variability.

- Oscillation of sinusoidal waves from above or below the baseline.

- Absence of accelerations.

- This pattern is observed in

- Severe anaemia with $\mathrm{Rh}$ isoimmunisation

- Fêto maternal haemorrhage

- Twin twin transfusion syndrome

- Severe fetal asphyxia

- Chorioamnionitis

\section{Unsatisfactory}

Tracing not adequate for interpretation.

Saltatory

Rapidly occurring couples of acceleration and deceleration causing relatively large oscillation of baseline FHR.

\section{Fetal heart rate patterns and its importance}

Characteristics of normal $F H R^{5,6}$

Baseline FHR is $120-160 \mathrm{bpm}$

Baseline beat to beat variability $\geq 6 \mathrm{bpm}$ for 15 seconds in 15 minutes.

No. of accelerations $\geq 2$ in $20 \mathrm{~min}$ period

Fetal outcome-vigorous with APGAR score $\geq 7$

Persistent fetal tachycardia

Tachycardia when FHR>160 bpm

Causes: amnionitis, maternal fever, fetal compromise, drugs 
Persistent fetal bradycardia

FHR $<120$ bpm is known as fetal bradycadia

Causes: Fetal compromise, congenital heart block in fetus, under general anaesthesia

\section{Fetal bradycardia with varied significance ${ }^{6}$}

Baseline bradycardia

FHR $<120$ bpm without co existent periodic changes and with adequate beat to beat variability.

\section{Prolong end stage deceleration}

Sudden drop in FHR in a patient who is near to deliver. The FHR 40-90 bpm is a product of vagal reflex by head compression.

\section{Bradycardia with lack of variability}

This ominous pattern occurs mainly in post term pregnancies. It may or may not be preceded by mild late deceleration.

\section{Bradycardia with deceleration}

Prolong bradycardia following late or severe variable deceleration

\section{FHR variability}

It is an index of fetal reserve or tolerance to hypoxic insults .Absent variability with late variable deceleration and fetal bradycardia shows hypoxic insults.

\section{Early deceleration}

Gradual decrease and return to baseline associated with contraction may be due to head compression.

\section{Late deceleration}

Due to uteroplacental insufficiency.

It is an indicator of fetal distress when they occur in context of decease variability and lack of acceleration.

\section{Variable deceleration}

Indicates fetal hypoxia due to cord compression specially in second stage of labour.

Mild: $<30$ sec duration

Moderate: $>30 \mathrm{sec}$ duration $<80 \mathrm{bpm}$

Severe: $<70 \mathrm{bpm}$ for $>60 \mathrm{sec}$ duration

\section{Ominous FHR pattern}

Absent FHR variability and shallow rate deceleration.

Absent FHR variability and mild variable deceleration with overshoot.

Absent or markedly decreased variability and prolonged bradycardia following severe variable or late deceleration.

\section{RESULTS}

Table 1 shows that $40 \%$ patients were between $20-24$ years. 30\% patients were between age 25-29 years of age. Maximum (70\%) of patients were in their second to third decade of life. This shows maximum fertility of the population.

Table 1: Effect of maternal age.

\begin{tabular}{|lll|}
$\begin{array}{l}\text { Maternal } \\
\text { age (years) }\end{array}$ & $\begin{array}{l}\text { No. of } \\
\text { patients } \\
(\mathrm{n}=50)\end{array}$ & $\begin{array}{l}\text { Percentage } \\
(\%)\end{array}$ \\
\hline$<20$ & 3 & $6 \%$ \\
\hline $20-24$ & 20 & $40 \%$ \\
\hline $25-29$ & 15 & $30 \%$ \\
\hline $30-34$ & 9 & $18 \%$ \\
\hline 35 or more & 3 & $6 \%$ \\
\hline
\end{tabular}

Table 2 shows that in our study, $48 \%$ having high risk factor were primigravida women. Although grand multiparity itself is a high risk pregnancy, in my study multipara were at less risk due to improved education and awareness.

Table 2: Effect of gravidity.

\begin{tabular}{|lll|}
\hline Gravidity & $\begin{array}{l}\text { No. of cases } \\
(\mathbf{n = 5 0})\end{array}$ & $\begin{array}{l}\text { Percentage } \\
(\%)\end{array}$ \\
\hline Primi & 24 & $48 \%$ \\
\hline Second & 13 & $26 \%$ \\
\hline Third & 8 & $16 \%$ \\
\hline Multigravida (>4) & 5 & $10 \%$ \\
\hline
\end{tabular}

In this study maximum number of patients $54 \%$ were between 34-36.6 weeks of gestational age. Followed by $22 \%$ women having gestational age between 31-33.6 weeks (Table 3).

Table 3: Effect of gestational age.

\begin{tabular}{|lll|}
$\begin{array}{l}\text { Gestational } \\
\text { age (weeks) }\end{array}$ & $\begin{array}{l}\text { No. of patients } \\
(\mathrm{n}=50)\end{array}$ & $\begin{array}{l}\text { Percentage } \\
(\%)\end{array}$ \\
\hline $32-33.6$ & 14 & $28 \%$ \\
\hline $34-36.6$ & 26 & $54 \%$ \\
\hline $37-39.6$ & 9 & $18 \%$ \\
\hline $40-42.6$ & 1 & $2 \%$ \\
\hline
\end{tabular}


Table 4 shows that majority of patients $(35 \%)$ had preeclampsias a major high risk factor followed by oligohydraminos (13\%).

Table 4: High risk factor affecting fetal electrocardiogram.

\begin{tabular}{|lll|}
\hline High risk factor & $\begin{array}{l}\text { No. of } \\
\text { patients } \\
(\mathrm{n}=50)\end{array}$ & $\begin{array}{l}\text { Percentage } \\
(\%)\end{array}$ \\
\hline PIH & 17 & $35 \%$ \\
\hline Eclampsia & 5 & $10 \%$ \\
\hline IUGR & 2 & $2 \%$ \\
\hline Anaemia & 5 & $10 \%$ \\
\hline Postdated & 5 & $10 \%$ \\
\hline Oligohydraminos & 6 & $13 \%$ \\
\hline Placenta praevia & 4 & $9 \%$ \\
\hline Chronic HTN & 5 & $10 \%$ \\
\hline Twins & 1 & $2 \%$ \\
\hline
\end{tabular}

Table 5 shows that majority of high risk women (52\%) underwent caesarean delivery while in $48 \%$ cases vaginal delivery was possible.

Table 5: Mode of delivery.

\begin{tabular}{|lll|}
\hline Mode of delivery & NST & \\
& Reactive & Non-reactive \\
\hline Vaginal delivery & $21(44 \%)$ & $3(4 \%)$ \\
\hline Caesarean & $4(6 \%)$ & $22(46 \%)$ \\
\hline
\end{tabular}

Table 6 shows that baby outcome is good when NST is reactive and only $22 \%$ children require resuscitation. In non-reactive NST $60 \%$ children needed resuscitation and only 1 baby expired due to meconium aspiration syndrome. This shows that NST has significant affect on perinatal outcome.

Table 6: Perinatal outcome according to NST reactivity.

\begin{tabular}{|lll|}
\hline NST & Baby well & $\begin{array}{l}\text { Baby needed NICU } \\
\text { admission }\end{array}$ \\
\hline Non-reactive NST & $9(40 \%)$ & $17(60 \%)$ \\
\hline Reactive NST & $18(77.77 \%)$ & $6(22.22 \%)$ \\
\hline
\end{tabular}

Table 7 shows that out of 23 patients who had nonreactive NST (19\%) had APGAR score <7 while 22\% children had APGAR score $>7$.

Table 7: Baby status at delivery 1 min APGAR score: According to the result of non-stress test.

\begin{tabular}{|lll|}
\hline NST reactivity & APGAR score $<7$ & APGAR score $>7$ \\
\hline $\begin{array}{l}\text { Reactive NST } \\
(\mathrm{n}=28)(1 \mathrm{twins})\end{array}$ & $4(9 \%)$ & $24(50 \%)$ \\
\hline $\begin{array}{l}\text { Non-reactive } \\
\text { NST }(\mathrm{n}=23)\end{array}$ & $11(19 \%)$ & $12(22 \%)$ \\
\hline
\end{tabular}

In patients with reactive NST only (9\%) had low APGAR score, while $50 \%$ children have APGAR score $>7$.

Table 8 shows that NST has good sensitivity of $71 \%$ with high specificity of $67 \%$.

Table 8: Outcome of fetal surveillance test.

\begin{tabular}{|lllll|}
\hline Test & Sensitivity & Specificity & PPV & NPV \\
\hline NST & $71.42 \%$ & $67.7 \%$ & $60 \%$ & $77 \%$ \\
\hline
\end{tabular}

*PPV - Positive predictive value

*NPV - Negative predictive value

Table 9 shows that study results are comparable to Rajgopal study as regional variabilities in different study may play a role.

Table 9: Comparison with other studies.

\begin{tabular}{|lllll|}
\hline Study & Sensitivity & Specificity & PPV & NPV \\
\hline $\begin{array}{l}\text { Present } \\
(\mathrm{n}=50)\end{array}$ & $71.42 \%$ & $67.7 \%$ & $60 \%$ & $77 \%$ \\
\hline $\begin{array}{l}\text { Dilmen } \\
(\mathrm{n}=121)\end{array}$ & $58.8 \%$ & $80.80 \%$ & $90.90 \%$ & $46.66 \%$ \\
$(1995)$ & & $85.71 \%$ & $60.00 \%$ & - \\
\hline $\begin{array}{l}\text { Rajgopal } \\
(\mathrm{n}=45) \\
(1996)\end{array}$ & $74.91 \%$ & & & \\
\hline
\end{tabular}

\section{DISCUSSION}

This study is conducted with maximum patients (40\%) of age group 20 to 24 years, mostly $(48 \%)$ primigravida having mean gestational age between 34 to 36.6 weeks.

This is a study of fetuses in 50 high risk cases monitored with non-stress test with cardiotocography in tertiary care center.

$36 \%$ had pregnancy induced hypertension $17 \%$ had oligohydraminos, $14 \%$ had postdate pregnancy. $7 \%$ had IUGR.

Many patients had combined high risk factors like $\mathrm{PIH}$ with oligohydraminos, anaemia, IUGR or postdate pregnancy with oligohydraminos. Most commonly seen high risk factor was PIH, eclampsia and postdate pregnancy with oligohydraminos.

Out of 50 patients $48 \%$ patients delivered vaginally either spontaneous or induced while $52 \%$ patients have undergone caesarean section due to various reasons like $\mathrm{PIH}$, fetal distress, postdate pregnancy, meconium stained liquor or post caesarean pregnancy.

Mode of delivery is also affected by reactivity of NST $46 \%$ of patients having non-reactive NST underwent caesarean section $6 \%$ having reactive NST underwent caesarean section. 
The individual parameters of poor fetal outcome like meconium stained liquor, APGAR score $<7$ at 5 minutes had increased incidence in non-reactive group.

Most common indication of LSCS in this study was PIH and related complications like eclampsia, HELLP syndrome, IUGR child, followed by fetal distress in $10 \%$ while post caesarean pregnancy was indication in $14 \%$, IUGR child was indicated in about $12 \%$. MSL and oligohydraminos were accounting for $20 \%$ cases. Postdate pregnancy and related complications accounted for about $5 \%$.

This suggests that nonreactive NST indicates fetal compromise, which can be further demonstrated by fetal scalp blood $\mathrm{pH}$, umbilical cord blood gas analysis or simply by low APGAR score at 1 and 5 minute.

Non Stress test less invasiveness, easy to use and easy interpretation makes it more easy and widely used.

Babies were well in $78 \%$ of reactive NST while $60 \%$ babies needed resuscitation in cases with non-reactive NST. Perinatal mortality was low and was due to meconium aspiration. $52 \%$ babies delivered by caesarean were healthy.

This shows that timely intervention in acidotic fetus can improve fetal outcome.

\section{CONCLUSION}

As in high risk pregnancies perinatal morbidity and mortality rate is very high, judicious use of electronic fetal monitoring can detect fetal hypoxia and metabolic acidosis at early stage and timely intervention can improve perinatal outcome.

Non Stress Test has sensitivity of $>71 \%$ and specificity of $>67 \%$. It can be used as a screening procedure in high risk cases to detect compromised fetus early.

Due to non-reactive Non-stress test helps us to timely intervene, improve fetal outcome and reduce fetal morbidity and mortality with reduced NICU admission rate by urgent delivery of fetus.

In developing countries like India in the periphery, where advanced equipments for fetal monitoring is not available, non-stress test is a very useful non-invasive screening test to detect and timely refer the high risk patient to a higher center where facilities for emergency obstetric care and NICU facilities are available.

\section{ACKNOWLEDGEMENTS}

We hereby would like to thank Dr. S. T. Malhan, the superintendent of Sheth V. S. general hospital, Dr. Pankaj R Patel, the dean of Smt N. H. L. municipal medical college to allow us to publish this paper.

Funding: No funding sources

Conflict of interest: None declared

Ethical approval: Not required

\section{REFERENCES}

1. Hon EH, Wohlgemuth R. The electronic evaluation of FHR IV. The effect of maternal exercise. Am J Obstet Gynaecol. 1961 Feb;81:361-71.

2. Declane Devane, Joan G. Lalor, Sean Daly, William McGuire, Valerie Smith. Cardiotocography versus intermittent auscultation of fetal heart $\mathrm{n}$ admission to labour ward. For assessment of fetal well-being. Cochrane Database Syst Rev. 2012 Feb;2:CD005122.

3. Bailey RE. Intrapatum fetal surveillance In: Leeman, eds. 1. Advanced Life support in Obstetrics Program: Provider Course Syllabus. Leawood: American Academy of Family Physicians; 2009.

4. American College of Obstetrician and Gynecologist, ACOG Practice Bulletin 145. Antepartum fetal surveillance. Obstet Gynaecol 2014;124:182-92.

5. F. Cunningham, Kenneth Leveno, Steven Bloom, John Hauth, Dwight Rouse, Catherine Spong. Intrapartum assessment. In: F. Cunningham, Kenneth Leveno, Steven Bloom, John Hauth, Dwight Rouse, Catherine Sponge, eds. Williams Obstetrics. 23rd ed. New York: McGraw Hill Publishing Division; 2009: 419-420.

6. Macones GA, Hankins GD, Spong CY, Hauth J, Moore T. The 2008 national institute of child health and human development workshop report on electronic fetal monitoring update on definitions, and research guidelines. J Obstet Gynaecol Neonatal Nurs. 2008;37(5):510-5.

7. Westgate JA, Wibbens B, Bennet L, Wassink G, Parer JT, Gunn AJ. The intrapartum deceleration in center stage: a physiological approach to the interpretation of fetal heart rate changes in labor. Am J Obstet Gynaecol. 2007;193(3):236.e1-11.

DOI: $10.5455 / 2320-1770 . i j r \operatorname{cog} 20141204$

Cite this article as: Goyal SG, Shah PT, Deliwala KJ. Role of fetal monitoring in high risk pregnancy by fetal electrocardiogram. Int J Reprod Contracept Obstet Gynecol 2014;3:893-7. 